\title{
Cardiothoracic surgery wellness: Now and the formidable road ahead
}

\author{
Romulo Fajardo, MD, ${ }^{\mathrm{a}}$ Ara Vaporciyan, MD, ${ }^{\mathrm{b}}$ Sandra Starnes, MD, ${ }^{\mathrm{c}}$ and Cherie P. Erkmen, $\mathrm{MD}^{\mathrm{d}}$
}

As a specialty, cardiothoracic surgery lacks a comprehensive approach to wellness. The medical community has already recognized that physician wellness impacts patient care and productivity. The lack of wellness, or burnout, has been associated with increased medical errors, lack of professionalism, and adverse patient outcomes. ${ }^{1-6}$ Burnout among physicians is also associated with poor patient compliance, low patient satisfaction, and increased medical malpractice suits. ${ }^{2,4-6}$ Burnout puts individual physicians at risk for substance abuse, intent to leave medical practice, and suicide. ${ }^{7}$ The suicide rate among male physicians is 1.41 times greater than the general population and even more pronounced in female physicians, who are 2.27 times more likely to commit suicide than the general population. ${ }^{8}$ At least $43.9 \%$ of physicians report at least 1 symptom of burnout, and overall, and $51.5 \%$ of trainees meet criteria for burnout. ${ }^{9}$ The attributable cost of physician burnout in the United States is approximately $\$ 4.6$ billion dollars annually, which equates to an annual cost of $\$ 7600$ per physician. ${ }^{10}$ The prevalence of physician burnout and its impact on physicians, patients, and institutions makes this issue critical to successful health care in the United States. ${ }^{11}$

Although wellness is a commonly discussed topic today in medicine, it is without a clear consistently conceptualized definition. In 2018, Brady and colleagues ${ }^{12}$ found that an overwhelming majority $(86 \%)$ of studies that assessed physician wellness did not provide a definition of the construct. Their review emphasizes the need for a shared and holistic definition of physician wellness and proposes the following conceptual definition: Physician wellness (well-being) is defined by quality of life, which includes the absence of ill-being and the presence of a positive physical, mental, social, and integrated well-being experienced

\footnotetext{
From the ${ }^{\mathrm{a}}$ Department of General Surgery, Temple University Hospital, Philadelphia, $\mathrm{Pa}$; ${ }^{\mathrm{b}}$ Department of Thoracic and Cardiovascular Surgery, University of Texas MD Anderson Cancer Center, Houston, Tex; ${ }^{\mathrm{c}}$ Division of Thoracic Surgery, University of Cincinnati College of Medicine, Cincinnati, Ohio; and ${ }^{\mathrm{d}}$ Thoracic Medicine and Surgery and Thoracic Surgery Residency Program, Lewis Katz School of Medicine at Temple University, Philadelphia, Pa.

Received for publication Oct 24, 2019; revisions received March 18, 2020; accepted for publication March 22, 2020; available ahead of print June 26, 2020.

Address for reprints: Romulo Fajardo, MD, Department of General Surgery, Temple University Hospital, 3401 N Broad St, C-401, Philadelphia, PA 19140 (E-mail: romuloandre.fajardo@tuhs.temple.edu).

J Thorac Cardiovasc Surg 2021;161:333-7

$0022-5223 / \$ 36.00$

Copyright (c) 2020 by The American Association for Thoracic Surgery

https://doi.org/10.1016/j.jtcvs.2020.03.178
}

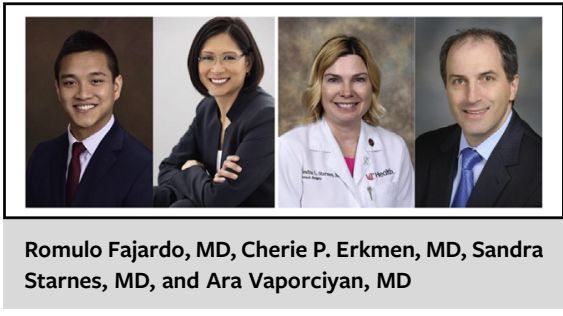

CENTRAL MESSAGE

Our goals are to promote a cultural shift toward wellness, emphasize the need for wellness education, and highlight how we can promote wellness in the field of cardiothoracic surgery.

See Commentaries on pages 338 and 339.

in connection with activities and environments that allow physicians to develop their full potential across personal and work-life domains.

\section{WELLNESS AMONG SURGEONS}

Surgeons are at high risk for burnout. With rigorous work hours, physical demands of surgery, and personal sacrifices for their professional practices, nearly $40 \%$ of American surgeons met criteria for burnout. ${ }^{13}$ Surgical residency has been characterized as a critically stressful life event. ${ }^{1,2}$ The consequences of burnout among surgeons are grave. The number of major errors by surgeons with major burnout is triple that of those with minimal burnout. ${ }^{14}$ There are few studies reporting on wellness or burnout among cardiothoracic surgeons. However, we can extrapolate that the stress, intensity of schedule, and rigors of cardiothoracic surgery put our community at particular risk. ${ }^{15}$ In 2011, Balch and colleagues ${ }^{16}$ found that cardiothoracic surgeons tested higher on depression screening assessments, had lower mental health quality of life scores, and exhibited a greater incidence of suicidal ideation in comparison with 14 other surgical specialties. In the field of cardiothoracic surgery, valuing wellness seems in contradiction to the fundamental values of perseverance and endurance. 
Cardiothoracic training can be especially challenging to individual surgeon wellness, largely because of the many changes experienced in residency and fellowship. Up to the point of residency, trainees choose their own personal sacrifices to reach academic achievements. In contrast, surgical residents and fellows must accept a transition to a hierarchal setting where the goals are patient-oriented, not self-oriented. Every year of training, roles change and responsibilities increase. These constant transitions can themselves create stress. Through the several years of cardiothoracic training, people may also experience increased responsibility in their personal lives, including childcare and the need to care for aging family members. In general, residency and fellowship place trainees at high risk for burnout, especially if they do not have adequate coping mechanisms or institutional support.

Transitioning to independent practice following surgical training is equally if not more challenging. There is a misconception among trainees that achieving the goal of independent practice will relieve them from the stressors experienced in training. As that may be partially true, the added responsibility in patient care, lack of protection for work hours, and the required familiarity with malpractice and billing issues all contribute to the potentially debilitating stress of being a junior attending. Currently, there is no formal training during residency/fellowship on malpractice, coding, billing, hospital politics, or financial planning that could potentially mitigate some of the stressors of transitioning to independent practice. There is no way to prepare trainees completely for the next stage, but perhaps implementing a "transitioning to clinical practice" learning series into the current surgical education curriculum would provide trainees with a standard foundation of knowledge moving forward. This along with burnout/fatigue education would give trainees a foundation of wellness, self-awareness, and personalized mechanisms for resiliency and a smooth transition to independent practice. In 2020, Fiedler and Sihag ${ }^{17}$ discuss the numerous stressors that a junior faculty member may experience as a young cardiothoracic surgeon and offer advice for success and tips for transitioning to practice.

\section{WHAT HAS ALREADY BEEN DONE TO ADDRESS WELLNESS?}

In 2017, the Association of American Medical Colleges, the National Academy of Medicine, and the Accreditation Council for Graduate Medical Education (ACGME) developed mandatory requirements for wellness for physician trainees. These requirements include giving trainees the opportunity to attend medical, mental health, and dental care appointments; educating faculty and residents about burnout; and mechanisms to alert leadership when concerns arise. In 2017, Squiers and colleagues ${ }^{14}$ called for advocacy for physician wellness among cardiothoracic surgeons.
These authors suggest that surgeon wellness and burnout should be treated as a disease continuum. As a profession, we should manage this disease process through maintenance of wellness, as well as prevention, assessment, and treatment of burnout. In May of 2019, the Society of Thoracic Surgeons Thoracic Surgery Director's Association (TSDA) meeting offered a workshop to Thoracic Surgery Program Directors on wellness. The objective was to define the requirements of wellness and share experiences with implementation.

Program Directors reported that cardiac and thoracic training programs and their parent institutions have not embraced physician wellness as a priority for several reasons. First, the concept of physician wellness is vague and thus difficult to characterize, measure, and manage. ${ }^{12}$ Thoracic surgery has traditionally perceived wellness as an individual responsibility, not the responsibility of training programs. If individuals could not achieve wellbeing or resiliency, perhaps they are not suited for cardiothoracic surgery. Even current assessment tools for wellness are directed at the individual, further propagating the concept that wellness is an individual responsibility. However, mounting evidence demonstrates that the work environment is responsible for physician burnout. ${ }^{18,19}$ The training environment that thoracic surgeons create can influence resident and fellow wellness. Among residents, work-hour reduction was associated with decreased emotional exhaustion and burnout among residents. ${ }^{20}$ For the successful implementation of wellness policies into training programs, our profession must accept a paradigm shift: wellness is not only an individual concern but a value among all cardiothoracic surgeons.

Second, the successful implementation of wellness requires institutional support. Institutionally governed workload, control and flexibility of schedule, efficiency of resources, and organizational culture are all influencers of physician wellness and burnout. ${ }^{21}$ Several studies have demonstrated that organizational strategies to address physician wellness can improve wellness and mitigate burnout. $^{22,23}$ Institutional responsibility for wellness is widely accepted in safety-critical jobs, such as those in transportation and air travel. ${ }^{24}$ In the safety-critical profession of cardiothoracic surgery, wellness of the surgeon should also be an institutional standard. Cardiac and thoracic surgeons must have institutional support to promote wellness.

Third, there is a lack of evidence within the field of cardiothoracic surgery on wellness. Our specialty attracts individuals of particular character and determination to manage the rigors of cardiothoracic practice. Wellness training to individuals who may already exhibit aboveaverage resiliency may not impact wellness. ${ }^{25}$ Additional specialty-specific data on the effects of wellness and 
TABLE 1. Wellness and fatigue table of resources

\begin{tabular}{|c|c|c|c|}
\hline \multirow[t]{5}{*}{$\begin{array}{l}\text { Screening } \\
\text { assessment/ } \\
\text { tools }\end{array}$} & $\begin{array}{l}\text { Mayo Clinic } \\
\text { 9-Question } \\
\text { Well-Being index } \\
\text { AMA's STEPS Forward modules }\end{array}$ & $\begin{array}{l}\text { https://www.mededwebs.com/ } \\
\text { well-being-index/resident-and- } \\
\text { fellow-well-being-index } \\
\text { https://edhub.ama-assn.org/steps- } \\
\text { forward/pages/professional- } \\
\text { well-being }\end{array}$ & $\begin{array}{l}\text { A screening tool to evaluate fatigue, } \\
\text { depression, burnout, anxiety/stress, and } \\
\text { mental/physical quality of life } \\
\text { Tools offering strategies on how to engage } \\
\text { health system leadership, understand } \\
\text { physician burnout and how to address it, as } \\
\text { well as develop a culture that supports } \\
\text { physician well-being }\end{array}$ \\
\hline & $\begin{array}{l}\text { MBI (Maslach Burnout } \\
\text { Inventory): Human Services } \\
\text { Survey for Medical Personnel }\end{array}$ & $\begin{array}{l}\text { https://www.mindgarden.com/ } \\
\text { 315-mbi-human-services- } \\
\text { survey-medical-personnel }\end{array}$ & $\begin{array}{l}\text { Tool used to measure burnout in } 3 \text { scales: } \\
\text { (1) Emotional exhaustion } \\
\text { (2) Depersonalization } \\
\text { (3) Personal Accomplishment }\end{array}$ \\
\hline & $\begin{array}{l}\text { USPSTF's Patient Health } \\
\text { Questionnaire (PHQ-9) }\end{array}$ & $\begin{array}{l}\text { http://med.stanford.edu/fastlab/ } \\
\text { research/imapp/msrs/_jcr__ } \\
\text { content/main/accordion/ } \\
\text { accordion_content3/ } \\
\text { download_256324296/file.res/ } \\
\text { PHQ9\%20id\%20date } \% 2008 \text {. } \\
\text { 03.pdf }\end{array}$ & Tool used for depression screening \\
\hline & $\begin{array}{l}\text { Mental Health American (MHA): } \\
\text { Mental Health Screening Tools }\end{array}$ & $\begin{array}{l}\text { https://screening.mhanational. } \\
\text { org/screening-tools }\end{array}$ & $\begin{array}{l}\text { Tools used to screen for an array of mental } \\
\text { health conditions such as depression, } \\
\text { anxiety, eating disorders, addiction, etc. }\end{array}$ \\
\hline & $\begin{array}{l}\text { Professional Quality of Life Scale } \\
\text { (PROQOL)—Compassion } \\
\text { Satisfaction and Compassion } \\
\text { Fatigue }\end{array}$ & $\begin{array}{l}\text { http://www.proqol.org/uploads/ } \\
\text { ProQOL_5_English_Self- } \\
\text { Score_3-2012.pdf }\end{array}$ & $\begin{array}{l}\text { Tool used to measure the negative and } \\
\text { positive effects of helping others who } \\
\text { experience suffering and trauma }\end{array}$ \\
\hline \multirow[t]{2}{*}{$\begin{array}{l}\text { Discussions/ } \\
\text { awareness }\end{array}$} & $\begin{array}{l}\text { Physician Well-Being: The } \\
\text { ACGME and Beyond }\end{array}$ & $\begin{array}{l}\text { https://www.acgme.org/ } \\
\text { Newsroom/Blog/Details/ } \\
\text { ArticleID/6288/Physician- } \\
\text { Well-Being-The-ACGME-and- } \\
\text { Beyond }\end{array}$ & ACGME Newsroom/Blog \\
\hline & $\begin{array}{l}\text { Mayo Clinic's } \\
\text { Make the Difference: Preventing } \\
\text { Medical Trainee Suicide }\end{array}$ & $\begin{array}{l}\text { https://www.youtube.com/watch? } \\
\qquad \mathrm{v}=\mathrm{I} \text { GRRF9qEBA }\end{array}$ & $\begin{array}{l}\text { A collaboration between the Mayo Clinic and } \\
\text { the American Foundation for Suicide } \\
\text { Prevention for increasing awareness for } \\
\text { signs of depression and managing stress }\end{array}$ \\
\hline $\begin{array}{l}\text { Organizational } \\
\text { commitment } \\
\text { statements }\end{array}$ & National Academy of Medicine & $\begin{array}{l}\text { https://nam.edu/initiatives/ } \\
\text { clinician-resilience-and-well- } \\
\text { being/commitment-statements- } \\
\text { clinician-well-being/ }\end{array}$ & $\begin{array}{l}\text { Provides opportunities for organizations } \\
\text { across the country to discuss and share } \\
\text { plans of action to reverse clinician burnout } \\
\text { and promote clinician well-being }\end{array}$ \\
\hline Educational tools & $\begin{array}{l}\text { Duke University School of } \\
\text { Medicine's Life Program: } \\
\text { Learning to Address Impairment } \\
\text { and Fatigue to Enhance Patient } \\
\text { Safety }\end{array}$ & $\begin{array}{l}\text { https://sites.duke.edu/ } \\
\text { thelifecurriculum/files/2014/ } \\
\text { 05/Macy-teachersguide1.pdf }\end{array}$ & $\begin{array}{l}\text { A program designed to identify strategies that } \\
\text { may prevent fatigue or impairment and } \\
\text { provide an early warning system }\end{array}$ \\
\hline
\end{tabular}

AMA, American Medical Association; USPSTF, United States Preventive Services Task Force; ACGME, Accreditation Council for Graduate Medical Education.

burnout, and meaningful interventions among cardiothoracic surgeons are needed.

Fourth, many Program Directors are not aware of the resources available to support wellness. Assessment tools, training modules, and ACGME guidelines on wellness are available but not organized or consolidated for easy implementation into cardiothoracic surgery training programs.

Lastly, Program Directors do not have experience with implementing wellness. Programs may be looking for guidance on how to educate themselves and their faculty on wellness and burnout. There are no guidelines or shared 
experiences on how to develop a wellness policy and demonstrate efficacy of the policy, especially to the ACGME for ongoing accreditation of their programs.

To further this effort, we advocate for specific steps of implementation that our residencies and professional societies can take.

\section{WHAT CAN CARDIOTHORACIC SURGERY DO TO PROMOTE WELLNESS?}

- Culture shift to accept wellness through education of

- cardiothoracic surgeons through seminars, simulations, and online continuing medical education modules;

$\circ$ trainees as a curriculum topic or orientation seminar;

$\circ$ administrators and staff on the efforts to promote wellness; and

o institutional leadership on the value of wellness in terms of individual productivity, patient safety, and financial impact.

- Development of a joint Society of Thoracic surgeons/ American Association for Thoracic Surgery/TSDA committee:

$\circ$ define wellness and burnout for cardiothoracic surgeons;

$\circ$ develop a mission statement for wellness;

$\circ$ define institutional guidelines; and

$\circ$ promote and conduct research to assess wellness among cardiac and thoracic surgeons.

- Implementation of wellness assessment tools (Table 1):

$\circ$ individual assessment tools; and

o development of institutional assessment tools.

- Intervention plans for individuals with burnout:

$\circ$ treatment for those experiencing burnout;

$\circ$ crisis plans for those in need of immediate attention; and

$\circ$ commitment of colleagues and institution to support intervention plans.

- Development of a TSDA curriculum with educational modules:

○ define wellness, burnout, and resiliency;

- current evidence on the potential harmful effects of burnout to patients, surgeons, and their institutions;

$\circ$ what are the ACGME guidelines and how can they be monitored;

$\circ$ emphasize that throughout the careers of cardiac and thoracic surgeons, there will be stressors. We cannot prepare for every situation, but residency and fellowship training include developing strategies of coping and resilience.
It is the responsibility of the cardiothoracic professional societies, training institutions, and leaders in cardiothoracic surgery to devote a concerted effort toward culture change with regard to wellness. These steps must be logical and speak to a process of assessment of the problem among cardiothoracic surgeons, interventions to improve wellness, and the measurement of outcomes. We must also construct a clear, consistent, and conceptualized definition for physician wellness to truly advance our knowledge, education, and research. Failure to develop a consensus definition may limit its assessment, thus preventing our complete understanding. These endeavors would be too overwhelming for a single institution, or even a single professional society to undertake, but perhaps with the collaboration of several governing bodies within cardiothoracic surgery, we may have meaningful steps toward promoting wellness and mitigation of burnout. The most logical start would be a specialty-wide consensus statement on wellness and unified implementation of a wellness policy among cardiothoracic training programs. Future directions for the implementation of wellness include an open forum for shared resources, shared experiences, and best practices. We must aspire to invest in future generations of well cardiothoracic surgeons and allow awareness and spread of this culture change through education.

\section{Conflict of Interest Statement}

The authors reported no conflicts of interest.

The Journal policy requires editors and reviewers to disclose conflicts of interest and to decline handling or reviewing manuscripts for which they may have a conflict of interest. The editors and reviewers of this article have no conflicts of interest.

\section{References}

1. Shanafelt TD, West C, Zhao X, Novotny P, Kolars J, Habermann T, et al. Relationship between increased personal well-being and enhanced empathy among internal medicine residents. J Gen Intern Med. 2005;20:559-64.

2. Panagioti M, Geraghty K, Johnson J, Zhou A, Panagopoulou E, Chew-Graham C, et al. Association between physician burnout and patient safety, professionalism, and patient satisfaction: a systematic review and meta-analysis. JAMA Intern Med. 2018;178:1317-30

3. West CP, Huschka MM, Novotny PJ, Sloan JA, Kolars JC, Habermann TM, et al. Association of perceived medical errors with resident distress and empathy. JAMA. 2006;296:1071.

4. Grol R, Mokkink H, Smits A, Eijk JV, Beek M, Mesker P, et al. Work satisfaction of general practitioners and the quality of patient care. Fam Pract. 1985;2: $128-35$.

5. Dimatteo MR, Sherbourne CD, Hays RD, Ordway L, Kravitz RL, McGlynn EA, et al. Physicians characteristics influence patients adherence to medical treatment: results from the Medical Outcomes Study. Health Psychol. 1993;12: 93-102.

6. Haas JS, Cook EF, Puopolo AL, Burstin HR, Cleary PD, Brennan TA. Is the professional satisfaction of general internists associated with patient satisfaction? J Gen Intern Med. 2000;15:122-8.

7. Dyrbye LN, Thomas MR, Massie FS, Power DV, Eacker A, Harper W, et al. Burnout and suicidal ideation among U.S. medical students. Ann Intern Med. 2008; $149: 334$. 
8. Schernhammer ES, Colditz GA. Suicide rates among physicians: a quantitative and gender assessment (meta-analysis). Am J Psychiatry. 2004;161:2295-302.

9. West CP, Shanafelt TD, Kolars JC. Quality of life, burnout, educational debt, and medical knowledge among internal medicine residents. JAMA. 2011;396: 929-60.

10. Han S, Shanafelt TD, Sinsky CA, Awad KM, Dyrbye LN, Fiscus LC, et al. Estimating the attributable cost of physician burnout in the United States. Ann Intern Med. 2019;170:784-90.

11. Dyrbye LN, Shanafelt TD. Physician burnout: a potential threat to successful health care reform. JAMA. 2011:305:2009-10.

12. Brady KJS, Trockel MT, Khan CT, Raj KS, Murphy ML, Bohman B, et al. What do we mean by physician wellness? A systematic review of its definition and measurement. Acad Psychiatry. 2018;42:94-108.

13. Shanafelt TD, Balch CM, Bechamps GJ, Russell T, Dyrbye L, Satele D, et al. Burnout and career satisfaction among American surgeons. Ann Surg. 2009; 250:463-71.

14. Squiers JJ, Lobdell KW, Fann JI, DiMaio JM. Physician burnout: are we treating the symptoms instead of the disease? Ann Thorac Surg. 2017;104:1117-22.

15. Mikalauskas A, Širvinskas E, Marchertiené I, Macas A, Samalavičius R,

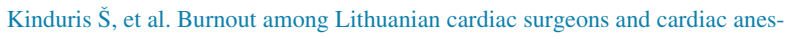
thesiologists. Medicina (Kaunas). 2012;48:478-84.

16. Balch CM, Shanafelt TD, Sloan JA, Satele DV, Freischlag JA. Distress and career satisfaction among 14 surgical specialties, comparing academic and private practice settings. Ann Surg. 2011;254:558-68.

17. Fiedler AG, Sihag S. Entering the great unknown: transition to academic practice. J Thorac Cardiovasc Surg. 2020;159:1156-60.
18. Williams ES, Konrad TR, Linzer M, McMurray J, Pathman DE, Gerrity M, et al Physician, practice, and patient characteristics related to primary care physician physical and mental health: results from the Physician Worklife Study. Health Serv Res. 2002;37:121-43.

19. Konrad TR, Williams ES, Linzer M, McMurray J, Pathman DE, Gerrity M, et al; SGIM Career Satisfaction Study Group. Measuring physician job satisfaction in a changing workplace and a challenging environment. Med Care. 1999;37: 1174-82.

20. Busireddy KR, Miller JA, Ellison K, Ren V, Qayyum R, Panda M. Efficacy of interventions to reduce resident physician burnout: a systematic review. J Grad Med Educ. 2017;9:294-301.

21. Shanafelt TD, Noseworthy JH. Executive leadership and physician well-being. Mayo Clinic Proc. 2017;92:129-46.

22. West CP, Dyrbye LN, Erwin PJ, Shanafelt TD. Interventions to prevent and reduce physician burnout: a systematic review and meta-analysis. Lancet. 2016;388:2272-81.

23. Panagioti M, Panagopoulou E, Bower P, Lewith G, Kontopantelis E, Chew-Graham C, et al. Controlled interventions to reduce burnout in physicians: a systematic review and meta-analysis. JAMA Intern Med. 2017; 177:195-205.

24. Hoffman S. Healing the Healers: Legal Remedies for Physician Burnout (September 5, 2018). Yale Journal of Health Policy, Law, and Ethics (2019, Forthcoming); Case Legal Studies Research Paper No. 2018-10. Available at: https://ssrn.com/abstract=3244831. Accessed October 12, 2019.

25. Card AJ. Physician burnout: resilience training is only part of the solution. Ann Fam Med. 2018;16:267-70 